Article

\title{
Study on the Behavior of BOPP Film Treated by Corona Discharge
}

\author{
Liping Ding ${ }^{1,+}$, Xiaoyong Zhang ${ }^{2,+}$ and Yanqing Wang ${ }^{1, *}$ \\ 1 School of Chemistry and Chemical Engineering, Nantong University, Nantong 226007, China; \\ dingliping@ntu.edu.cn \\ 2 School of Chemical Engineering and Technology, Harbin Institute of Technology, Harbin 150001, China; \\ xiaoyongzhang@hit.edu.cn \\ * Correspondence: ccewyq@ntu.edu.cn \\ + These authors contributed equally to this work.
}

Received: 8 October 2020; Accepted: 3 December 2020; Published: 7 December 2020

check for updates

\begin{abstract}
Corona discharge is widely used as a good surface pretreatment method for polymer materials. In this work, the attenuated total reflectance Fourier transform infrared spectrometry (ATR-FTIR), X-ray photoelectron spectroscopy (XPS), scanning electronic microscopy (SEM), and atomic force microscopy (AFM) were used to investigate the behavior of biaxially oriented polypropylene (BOPP) film treated by corona discharge. The possibly involved chemical reactions during the corona treatment process under atmosphere components were systematically summarized. This work lays a theoretical basis for improving the performance of BOPP films and expanding their application fields.
\end{abstract}

Keywords: corona discharge; BOPP film; physical etching effect; chemical oxidation effect

\section{Introduction}

Polypropylene (PP) as a thermoplastic resin is an important member of polyolefin (polyethylene, polypropylene, polybutylene) and is also one of five general synthetic resins (polyethylene, polystyrene, polypropylene, polyvinyl chloride, and acrylonitrile butadiene styrene plastic) [1,2]. It can be divided into two categories according to composition difference: homopolymer polypropylene and copolymer polypropylene [3-5]. Meanwhile, it includes three types based on structure difference: isotactic polypropylene, anisotropic polypropylene, and atactic polypropylene [6,7]. Because the biaxial stretch polypropylene (BOPP) film will undergo transverse and longitudinal stretching deformation in the molding process compared with that of the non-stretch film, the arrangement of its molecular chains or chain segments will be changed. Herein, the performance of the film is significantly improved [8-10]. Because BOPP film has excellent mechanical properties, chemical resistance, cold resistance, heat resistance, good barrier, and low price, it has become the most widely used packaging material and is known as the "packaging queen" [11-13]. Although BOPP film has many outstanding properties, its chemical structure does not contain active groups. Meanwhile, many reasons make it difficult to be wetted and bonded [14-16], such as high crystallinity, low surface energy, chemical inertness, surface pollution, and the existence of weak boundary layer. In particular, the poor wettability greatly limits the application of the BOPP film in ink, adhesives, composite materials, heat sealing, and coating area. Therefore, the secondary treatment of the BOPP film is necessary for improving its wettability and adhesion $[17,18]$. Scientists have developed many secondary treatment technologies, such as corona treatment, chemical surface grafting, acid oxidation, gamma irradiation, chemical coating, flame treatment, ion implantation, and so on. As we know, the corona treatment has the advantages of short time, fast speed, simple operation, and easy control [19-21]. Moreover, the corona 
treatment is especially beneficial for improving the surface activity of the substrate before the film printing, polymerization, recombination, and bonding processes [22-26]. However, the corona effect of the film is unstable, and it will degrade with the change of storage time or environment, so the as-treated material should be used instantly. The typical corona discharge processing diagram is shown in Scheme 1. After the corona discharge treatment, the carbonyl or nitrogen-containing polar functional groups can be generated on the molecular chain of the polymer material to meet the pretreatment requirements of top-grade printing, polymerization, coating, and gold stamping processes. Thus, the understanding of chemical reactions during corona treatment for BOPP film is essential to diverse downstream applications. Christine et al. proposed that the chemical mechanism of corona treatment is oxidation [22]. The oxidization reaction can produce the polar functional groups on the film, which can improve its surface energy, wettability, and adhesion property. Vishnuvarthanan et al. asserted that the oxygen plasma treatment can generate the oxygen-containing polar functional groups on the polypropylene film and induce the chemical composition variation of materials [23]. Mercado-Cabrera et al. proposed that the morphology of the polyprolylene film will change after plasma oxidation treatment [24]. Navaneetha Pandiyaraj et al. thought that the $\mathrm{C}=\mathrm{O}, \mathrm{O}-\mathrm{C}-\mathrm{O}$, and $\mathrm{C}-\mathrm{N}$ functional groups are incorporated on PP films after corona treatment, which will improve its wettability [25-27]. Dong et al. studied the mechanism of corona treatment of polyolefin films, specifically the chemical and physical changes of this process and put forward the self-adhesion mechanism [28]. Some researchers investigated the behavior of corona treatment for PP films. They generally thought that the surface properties of film are improved owing to a series of complex reactions from corona, such as surface cleaning, activation, crosslinking, and etching. However, the theoretical reactions of the corona discharge treatment for BOPP film have not been proved in detail until now and the involved chemical reaction processes are still unclear. For example, there is no specific theoretical study on how the oxidation reaction occurs, what groups are oxidized, and what the structural formula is after oxidation, and for chain scission and reorientation reaction, which molecular chain breaks and what the process of rearrangement reaction is.

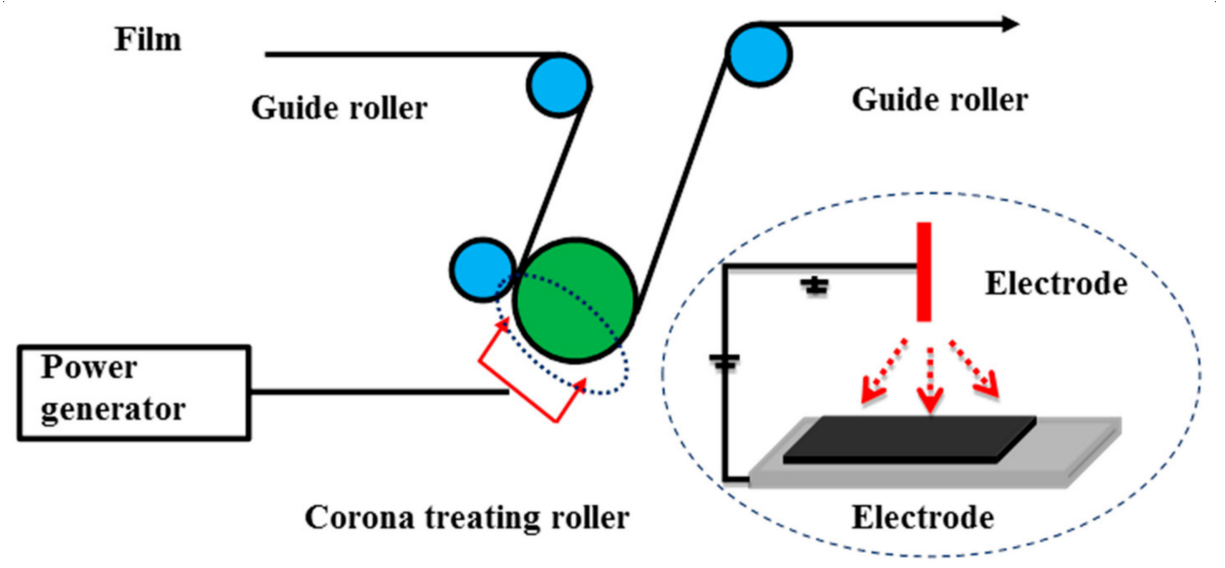

Scheme 1. The diagram of the corona treatment.

In this work, the chemical structure, morphologies, and topologies changes of corona BOPP film under different corona conditions were investigated to systematically understand the corona reactions. Importantly, the interaction reactions between corona treatment and the surface of BOPP film was proved and the chemical reactions during corona treatment were also proposed in detail, which will lay a theoretical foundation for improving the adhesion of BOPP film in printing inks, paints, adhesives, and other coating applications. 


\section{Experimental}

\subsection{The Corona Discharge Treatment for BOPP Film}

As shown in Scheme 1, we use corona processors to ionize the air between two electrodes under high voltage and excite the surface of BOPP film to produce polar functional groups. The BOPP film (thickness $20 \mu \mathrm{m}$ ) was provided by Wuxi Zhongyi Film Co., LTD. (Wuxi, Jiangsu, China). The corona processor was purchased from Zhejiang Zhengtai Electric Appliance Co., LTD. (Leqing, Zhejiang, China). The corona processor includes two $15 \mathrm{~mm} \times 15 \mathrm{~mm} \times 600 \mathrm{~mm}$ ceramic electrodes. The machining width is $500 \mathrm{~mm}$, the processing speed is $5-20 \mathrm{~m} / \mathrm{min}$, the input voltage is $220 \mathrm{~V}$, the output frequency is $15-20 \mathrm{kHz}$, the output voltage is $6-10 \mathrm{kV}$ and the maximum output power is $4 \mathrm{~kW}$. The corona processing speed is fixed at $15 \mathrm{~m} / \mathrm{min}$ and the output power and corona cycles are shown in Table 1. More corona cycles mean longer corona time.

Table 1. The experimental conditions of corona discharge treatment for the biaxially oriented polypropylene (BOPP) film.

\begin{tabular}{ccc}
\hline Sample & Corona Treatment Power $(\mathbf{k W})$ & Corona Cycles \\
\hline A & - & - \\
B & 2.0 & 3 \\
C & 3.0 & 3 \\
D & 3.0 & 7 \\
\hline
\end{tabular}

\subsection{Characterization}

A Nicolet-Nexus 670 Fourier transform infrared spectrometer (Waltham, MA, USA) was used to determine the chemical structure of BOPP film and corona BOPP film under the attenuated total reflection (ATR) mode. The ATR crystal material is diamond, the resolution is $4 \mathrm{~cm}^{-1}$ and the number of scans is 32. The chemical composition of BOPP film and corona BOPP film was detected by PHI5700 XPS spectrometer (Physical Electronics Inc., Chanhassen, MN, USA). The X-ray source is Al $\mathrm{Ka}(1253.6 \mathrm{eV})$, the voltage is $12.5 \mathrm{kV}$, the current is $20 \mathrm{~mA}$, and the background vacuum is $10^{-7} \mathrm{~Pa}$. XPSPEAK software 4.1 as used for data collection and processing. For high-resolution XPS analysis of $\mathrm{C} 1 \mathrm{~s}$ and $\mathrm{N} \mathrm{1s}$, the total acquisition time is $3 \mathrm{~min}$, the number of scans is 10 , the source gun type is $\mathrm{Al} \mathrm{K} \alpha$, the lens mode is standard, the pass energy is $30.0 \mathrm{eV}$, the energy step size is $0.050 \mathrm{eV}$, and the number of energy steps is 401 . The surface morphology of BOPP film and corona BOPP film was observed by SEM (FEI Quanta 200, Hillsboro, OR, USA). The voltage is $10 \mathrm{kV}$ and the surface of samples should be sputtered with gold for $10 \mathrm{~min}$. The surface topology and surface roughness of BOPP film and corona BOPP film were investigated by AFM (Dimension Icon-PT, Ettlingen, Germany). The scanning rate was $1.0 \mathrm{~Hz}$, the test area of the sample is $5 \mu \mathrm{m} \times 5 \mu \mathrm{m}, X-Y$ axis resolution is less than $0.1 \mathrm{~nm}$, and the $Z$ axis resolution is less than $0.03 \mathrm{~nm}$. The roughness of each sample was obtained by calculating the average roughness of two samples based on AFM images. All the data was processed by the NanoScope software (version: 1.5).

\section{Results and Discussion}

\subsection{The Analysis of the Surface Chemical Structure of Corona BOPP Film}

As shown in Figure 1, Sample a represents pristine BOPP film and the absorption peaks at 2950 and $2872 \mathrm{~cm}^{-1}$ correspond to the absorption peaks of methyl symmetric and asymmetric stretching vibrations, respectively [23]. For Sample a, the absorption peaks at 2920 and $2840 \mathrm{~cm}^{-1}$ are methylene symmetric and asymmetric stretching vibrations peaks, respectively (Figure 1C). The absorption peaks at 1457 and $1379 \mathrm{~cm}^{-1}$ are scissor vibration absorption peaks of methyl and methylene, respectively [23]. The relatively weak absorption peak of $800-1200 \mathrm{~cm}^{-1}$ belongs to methenylene absorption peak (Figure 1B) [21]. Sample b, Sample c, and Sample d represent corona BOPP film with different corona 
treatment conditions. The corona parameters are shown in Table 1. Compared with the pristine BOPP film, a new chemical structure is found on the surface of corona BOPP film. As shown in Figure 1D, these new chemical groups become more obvious with the increment of the corona output voltage (Sample $b$ and Sample c) and corona time (Sample c and Sample d). However, methyl and methylene absorption peaks decrease with the increment of corona output voltage and corona time. The absorption peaks at 907-1341 $\mathrm{cm}^{-1}, 1537-1858 \mathrm{~cm}^{-1}$ and 3100-3600 $\mathrm{cm}^{-1}$ become wider (Figure 1B,C). Moreover, the

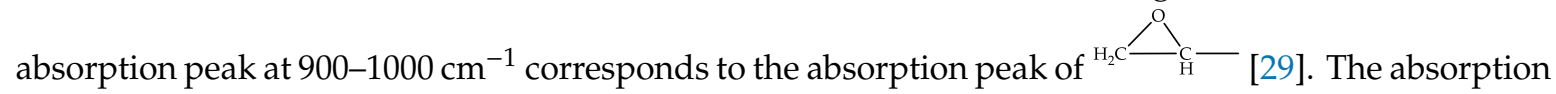
peak of 1110-1300 $\mathrm{cm}^{-1}$ belongs to ester group (C-O) [30]. The absorption peak at 1537-1858 $\mathrm{cm}^{-1}$ corresponds to carbonyl absorption peak [30], the absorption peak at $1350 \mathrm{~cm}^{-1}$ belongs to nitrate absorption peak, and the broad absorption peak at 3100-3600 $\mathrm{cm}^{-1}$ comes from the amino group and hydroxyl group absorption peak [31,32]. These new absorption peaks can be attributed to the crack of chemical bonds (e.g., methyl and methylene) on the surface of BOPP film, which are caused by corona discharge treatment and the formation of free radicals. The content of methyl and methylene of sample $\mathrm{d}$ in Figure $1 \mathrm{C}$ is significantly lower than that in sample a, which can also confirm that methyl and methylene are broken or decomposed. In the presence of nitrogen, oxygen, and ozone in the air, free radicals participate in a series of chemical reactions and polar functional groups containing oxygen are formed, such as aldehydes, ketones, carboxylic acids, carbonyl groups, hydroxyl groups, esters, etc. The detailed ATR-FTIR data is shown in Table 2.
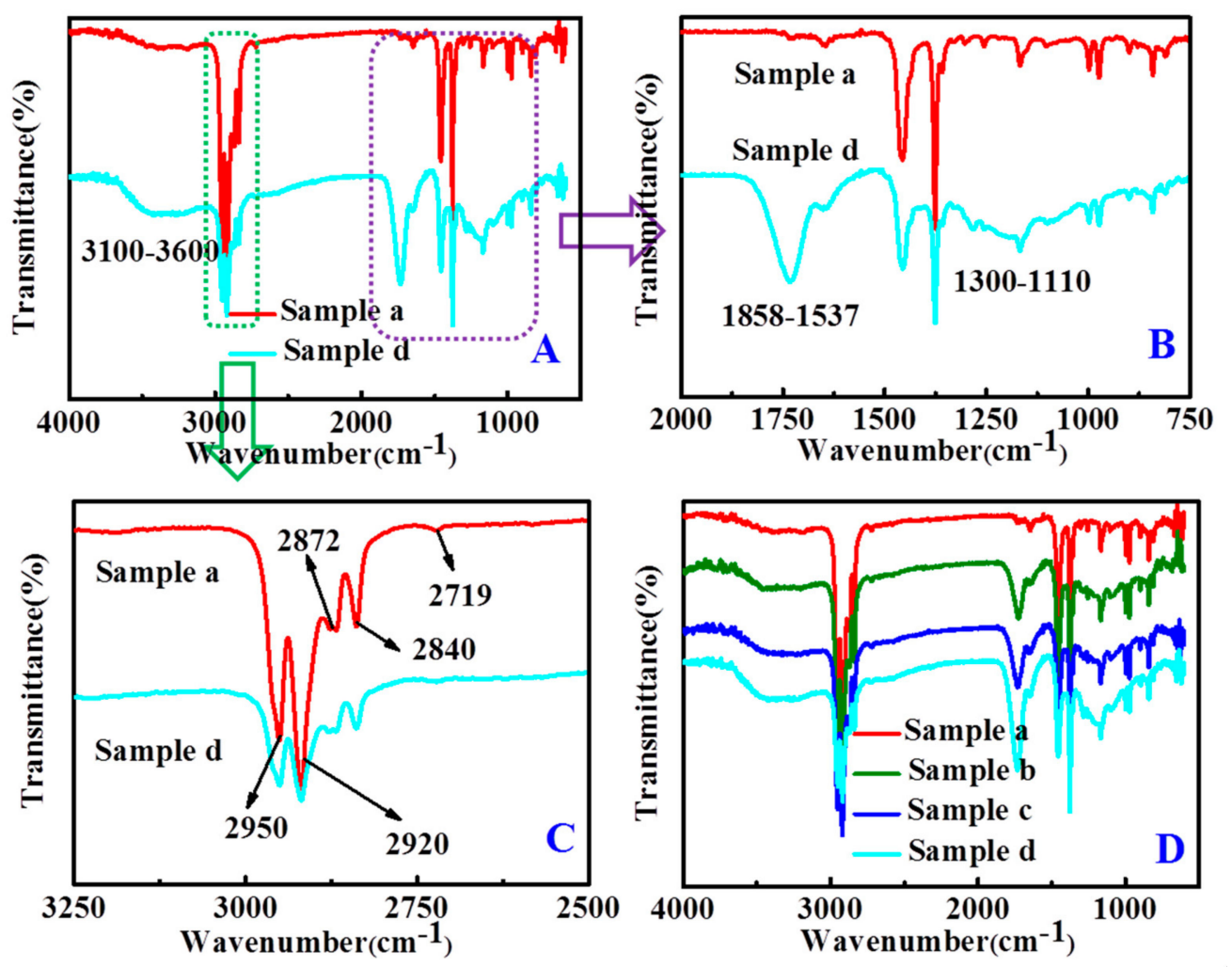

Figure 1. The ATR-FTIR spectra of BOPP films under different corona treatment conditions. (A) is the infrared spectra of sample a and sample d. $(\mathbf{B}, \mathbf{C})$ is the local magnification of the infrared spectra of sample a and sample d. (D) is a comparative infrared spectra of sample a, sample b, sample c and sample d. 
Table 2. The ATR-FTIR results of pristine BOPP film and corona BOPP film.

\begin{tabular}{|c|c|c|}
\hline Title & $\begin{array}{c}\text { Wavenumber, } \\
\mathrm{cm}^{-1}\end{array}$ & The Corresponding Group \\
\hline \multirow{3}{*}{ pristine BOPP film } & 2950,2872 & $-\mathrm{CH}_{3}$ \\
\hline & 2920,2840 & $-\mathrm{CH}_{2-}$ \\
\hline & 2719 & $\mathrm{CH}$ \\
\hline \multirow{5}{*}{ Corona BOPP film } & $3100-3600$ & $-\mathrm{NH}_{2},-\mathrm{OH}$ \\
\hline & 1350 & $\mathrm{R}-\mathrm{NO}_{2}$ \\
\hline & $900 \sim 1000$ & \\
\hline & 1537-1858 & $-\mathrm{COOH}$ \\
\hline & $1110-1300$ & $\mathrm{C}-\mathrm{O}-$ \\
\hline
\end{tabular}

As shown in Table 3 and Figure S1, the pristine BOPP film mainly contains carbon element. The existence of $\mathrm{N}(2.52 \%)$ and $\mathrm{O}(5.9 \%)$ element on the surface of BOPP film is due to the adsorption of nitrogen and oxygen in the air. Table 3 and Figure S1 show that the oxygen content of corona BOPP film increases obviously and the content of oxygen element increases with the increment of corona output voltage (Sample b and Sample c) and corona time (Sample c and Sample d). The increment of oxygen content on the surface of the film is attributed to the discharge phenomenon of the electrode on the surface of the film, which will result in the fracture of chemical bonds and the formation of free radicals. These free radicals will combine with oxygen to form oxygen-containing functional groups. Notably, the nitrogen content of BOPP film decreases after corona discharge treatment. The reason is that the physical adsorption effect of nitrogen molecules on film is removed by high voltage electric shock. Meanwhile, the remaining nitrogen element is formed by the chemical reaction of nitrogen molecules in air on the surface of the film at high voltage.

Table 3. The element composition of pristine BOPP film and corona BOPP film.

\begin{tabular}{cccccc}
\hline \multirow{2}{*}{ Sample } & \multicolumn{3}{c}{ Element Composition (at.\%) } & \multicolumn{3}{c}{ Ratio } \\
\cline { 2 - 6 } & $\mathbf{C}$ & $\mathbf{O}$ & $\mathbf{N}$ & $\mathbf{O} / \mathrm{C}$ & N/C \\
\hline $\mathrm{A}$ & 91.57 & 5.90 & 2.52 & $6.40 \%$ & $2.7 \%$ \\
$\mathrm{~B}$ & 77.44 & 20.8 & 1.41 & $26.9 \%$ & $1.8 \%$ \\
$\mathrm{C}$ & 76.33 & 21.96 & 1.71 & $28.8 \%$ & $2.2 \%$ \\
$\mathrm{D}$ & 75.84 & 22.59 & 1.57 & $29.8 \%$ & $2.1 \%$ \\
\hline
\end{tabular}

To further investigate the involved chemical reactions during the corona discharge treatment, A high-resolution XPS analysis of $C 1$ s and $N$ 1s peaks was performed. The $C 1$ s spectrum of pristine BOPP film mainly contains $\mathrm{C}-\mathrm{C} / \mathrm{C}-\mathrm{H}$ functional groups, which is consistent with the chemical structure of polypropylene. A very small amount of oxygen also is found on the film, which is a typical property of hydrocarbon film under the air atmosphere [33]. After the corona discharge treatment, $\mathrm{C}-\mathrm{O}(286.3 \mathrm{eV}), \mathrm{C}=\mathrm{O} / \mathrm{O}-\mathrm{C}-\mathrm{O}(287.8 \mathrm{eV})$, and $\mathrm{O}-\mathrm{C}=\mathrm{O}(289.1 \mathrm{eV})$ peaks are introduced onto the BOPP film (Figure 2 Sample b, Sample c and Sample d). The results show that aldehydes, ketones, carboxylic acids, carbonyl groups, hydroxyl groups, esters, peroxides, and other oxygen-containing groups are formed on the surface of the BOPP film after the corona discharge treatment $[26,34,35]$. As shown in Figure 3, the peaks in $\mathrm{N}$ 1s spectrum belong to the groups of the amide $(399.8 \mathrm{eV}),-\mathrm{NO}_{2}(402.2 \mathrm{eV})$ 
and $-\mathrm{NO}_{3}(407.6 \mathrm{eV})$. The pristine BOPP film only contains a single peak from the $-\mathrm{NH}_{2}(399.8 \mathrm{eV})$ functional group (Figure 3 Sample a) while the absorption peaks of 402.2 and $407.6 \mathrm{eV}$ of corona BOPP film come from the functional group absorption peaks of $-\mathrm{NO}_{2}$ and $-\mathrm{NO}_{3}$, respectively (Figure 3 Sample b, Sample c, and Sample d). The corona discharge treatment can transfer energy onto the surface of BOPP film and cause the crack of chemical bonds, which can react with nitrogen to form the nitrogen functional groups under oxygen atmosphere.
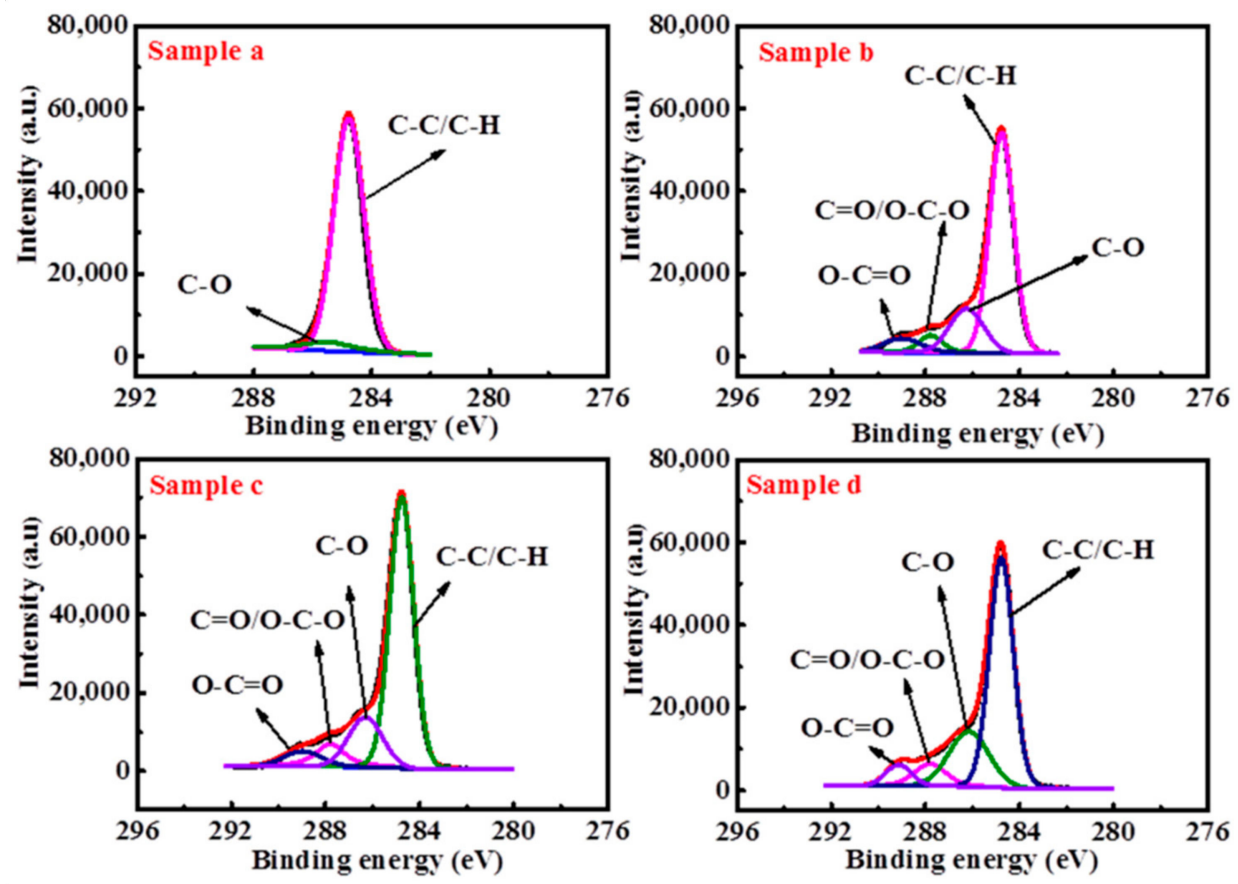

Figure 2. The XPS C 1s spectra of pristine BOPP film and corona BOPP film for different samples.
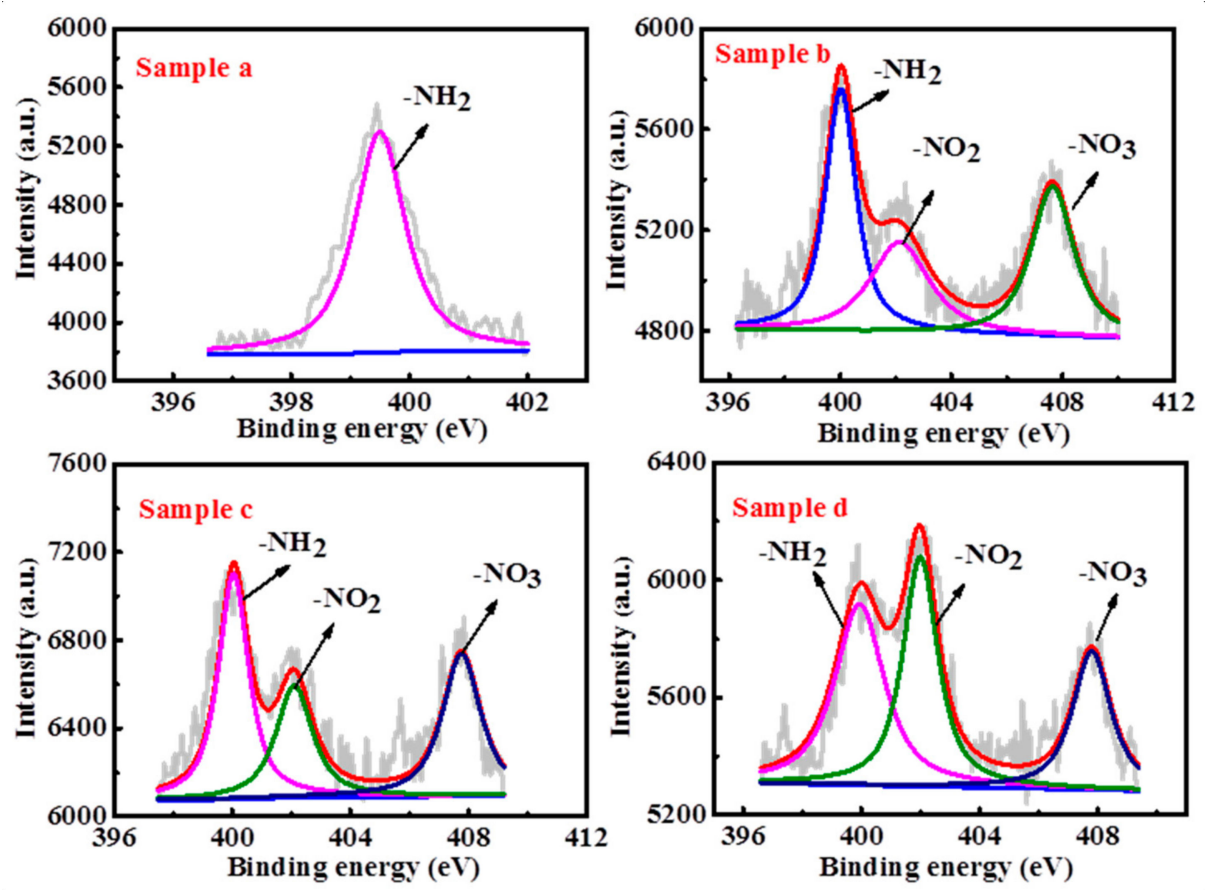

Figure 3. The XPS N 1s spectra of pristine BOPP film and corona BOPP film for different samples.

Based on the test results of ATR-FTIR and XPS, the involved chemical reactions of corona BOPP film are summarized in detail. Corona discharge treatment refers to complex reaction processes. 
Moreover, oxygen-containing polar functional groups, nitrogen-containing polar functional groups and some small free radicals are all produced during corona discharge treatment. Meanwhile, high voltage electron shock can effectively remove water vapor, oil and dust from the surface of the film. The related chemical reactions are shown in Scheme 2.

I. Oxidation reaction<smiles>CC(C)CCCCCCC(C)(C)O[O+]</smiles>

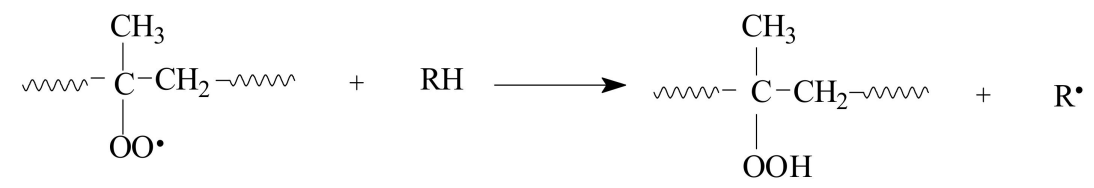<smiles>CC(C)(O)CCCCCCC(C)(C)O</smiles>

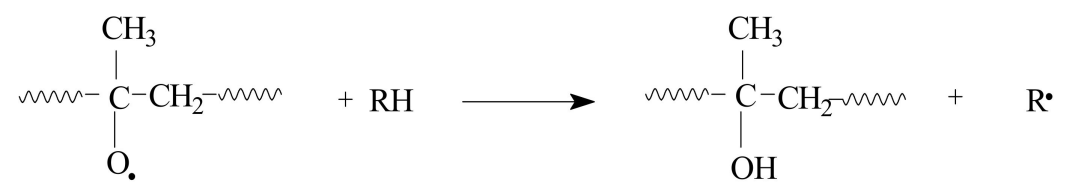

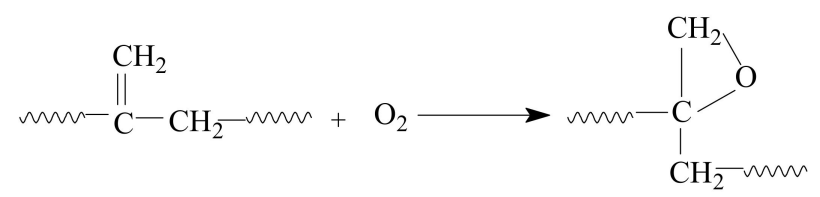

II. Chain scission and reorientation reaction

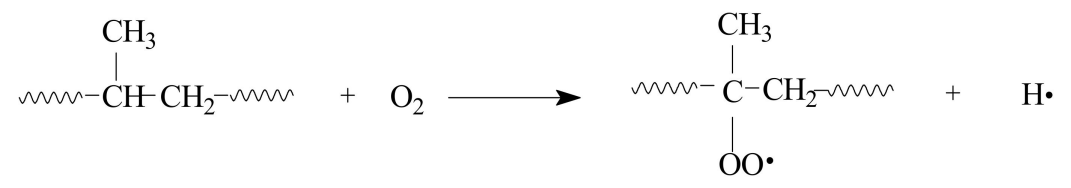<smiles>CC(C)(CCCO)CCCCC(C)(C)O[O+]</smiles><smiles>CC(=[OH+])CCCCCC(C)(O)CC(C)(O)O</smiles><smiles>C=C(CCCCCCC(C)C[N+](=O)[O-])COC</smiles>

Scheme 2. Cont. 
<smiles>CC(C)CCOCCCCC(C)C(C)O[Na]</smiles>

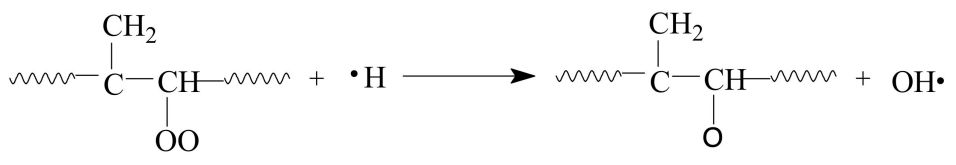

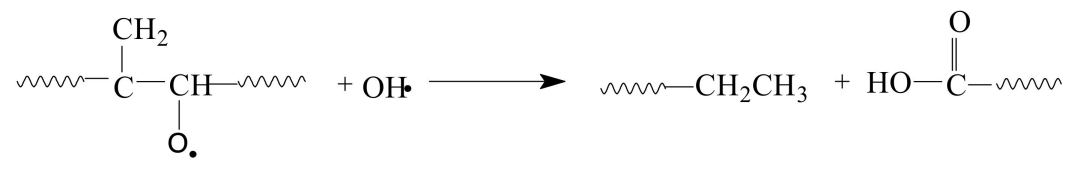

III. Nitride reaction

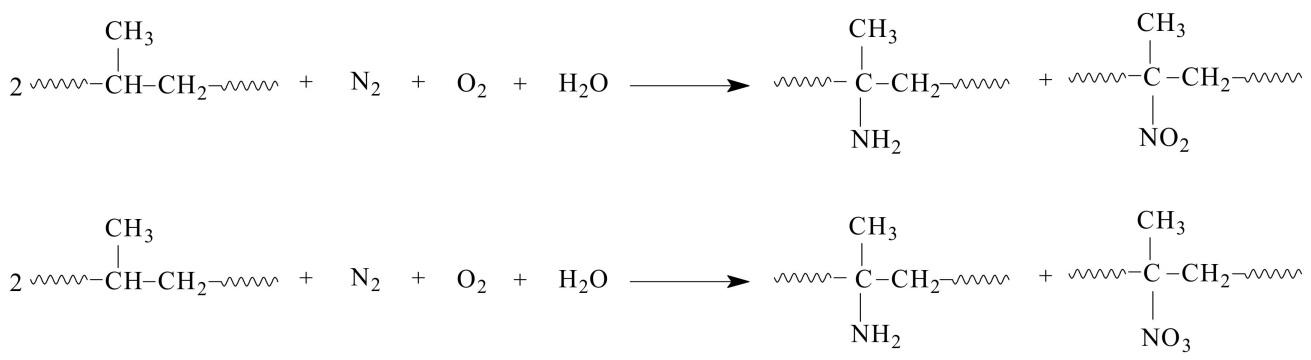

Scheme 2. The involved chemical reactions of BOPP film during corona discharge treatment.

\subsection{The Analysis of Surface Morphology and Topology of Corona BOPP Film}

The surface morphology and topology of pristine BOPP film and corona BOPP film was measured by SEM and AFM. As shown in Figure 4, the surface of pristine BOPP film is all smooth at different magnification rates (Figure 4 Sample a) while the surface of corona BOPP film presents a lot of uniform and uneven bulges (Figure 4 Sample b, Sample c, and Sample d). The increment of the surface roughness of the corona BOPP film is due to the fracture of polymer chains during the corona treatment. The etching effect onto pristine BOPP film becomes more obvious with the increment of the corona time and the corona power. The impact points can be clearly seen at the same magnification rates especially in magnification SEM images of Sample $d$, which are attributed to the bump onto the film owing to the electron flow during high voltage discharge.
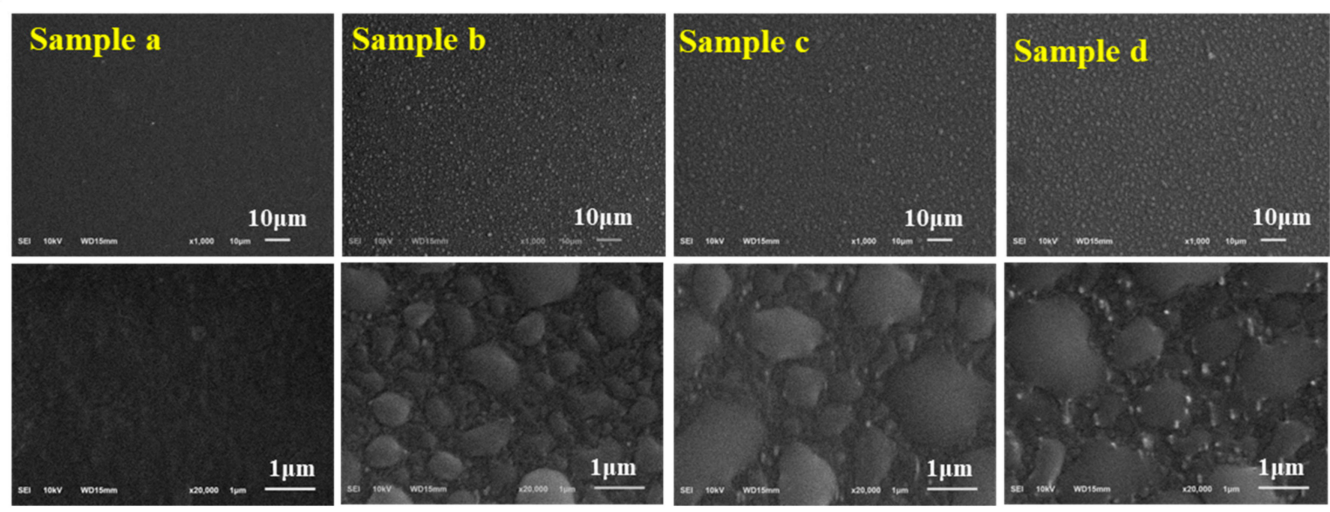

Figure 4. SEM images of pristine BOPP film and corona BOPP film for different samples.

As shown in Figure 5, many bulges appear on the surface of corona BOPP film and the bulge volume increases gradually with the increment of the corona time and corona output voltage. In the 
AFM image of Sample d, because Sample d has the longest corona output voltage and corona time, small bulges become large bulges. The average surface roughness of BOPP film rises from $7.81 \mathrm{~nm}$ to $59.8 \mathrm{~nm}$ (Supplementary Materials Table S1), which is consistent with the SEM test results and is attributed to the formation of many high-energy substances under high pressure. When high-energy particles strike the surface of the film, tiny pits are formed. The interaction between electron and the surface of PP film can also lead to surface etching effect by the rapid removal of low molecular pollutants, such as additives, processing aids, etc. In addition, the molten materials or sputtered fragments are heated and evaporated in the interaction region through the adsorption of electron energy, which can result in the changes of surface topology and roughness. The surface roughness of the corona film depends on the properties of the electron beam. With the increment of electron beam flow, the surface energy of polymer increases, and the surface roughness of the film is improved.

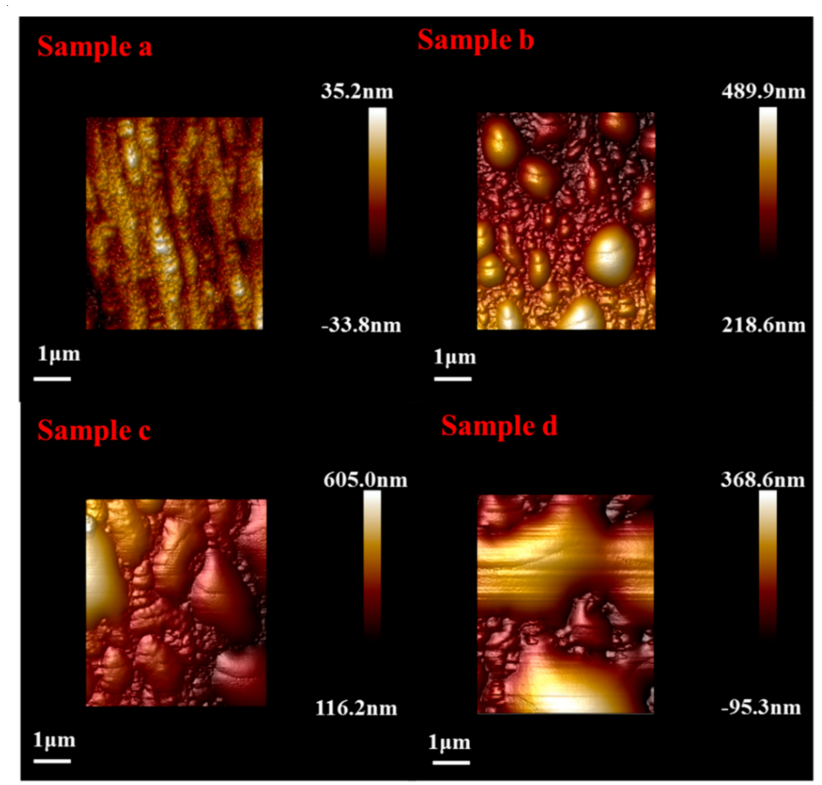

Figure 5. AFM topology of pristine BOPP film and corona BOPP film for different samples.

\section{Conclusions}

In this work, the behavior of corona BOPP film was systematically studied by FT-IR, XPS, SEM, and AFM. The possibly involved oxidation reaction, chain breaking reaction, redirection reaction, and nitriding reaction during the corona discharge treatment were summarized in detail. In the corona discharge process, the high voltage treatment of BOPP film leads to the crack of molecular chains and the formation of free radicals on the surface of the film. These free radicals can react with air to form polar oxygen or nitrogen-containing functional groups. Meanwhile, the gas molecular is dissociated into charged substances under high voltage, which bombard the film and make the surface of the film coarsening. These synergistic effects can finally achieve the purpose of the surface pretreatment for the BOPP film.

Supplementary Materials: The following are available online at http://www.mdpi.com/2079-6412/10/12/1195/s1, Figure S1: XPS wide scan spectra of untreated BOPP film and corona treated BOPP film, Table S1: The statistic on roughness values.

Author Contributions: Conceptualization, L.D.; methodology, L.D.; writing-original draft preparation, L.D.; investigation, X.Z.; writing-review and editing Y.W. All authors have read and agreed to the published version of the manuscript.

Funding: This research received no external funding.

Acknowledgments: The author is very grateful to Peng Zhu and Haiyan Ma for their valuable advice and help in this work. 
Conflicts of Interest: The authors declare no conflict of interest.

\section{References}

1. Zhou, T.Y.; Tsui, G.C.P.; Liang, J.Z.; Zou, S.Y.; Tang, C.Y.; Mišković-Stanković, V. Thermal properties and thermal stability of PP/MWCNT composites. Compos. Part B Eng. 2016, 90, 107-114. [CrossRef]

2. Liu, J.; Zhu, X. Isotactic polypropylene toughened with poly(acrylonitrile-butadiene-styrene): Compatibilizing role of maleic anhydride grafted polypropylene. Polym. Eng. Sci. 2019, 59, E317-E326. [CrossRef]

3. Ota, Y.; Ito, S.; Kobayashi, M.; Kitade, S.; Sakata, K.; Tayano, T.; Nozaki, K. Crystalline isotactic polar polypropylene from the palladium-catalyzed copolymerization of propylene and polar monomers. Angew. Chem. Int. Ed. 2016, 55, 7505-7509. [CrossRef] [PubMed]

4. Green, C.D.; Vaughan, A.S.; Stevens, G.C.; Pye, A.; Sutton, S.J.; Geussens, T.; Fairhurst, M.J. Thermoplastic cable insulation comprising a blend of isotactic polypropylene and a propylene-ethylene copolymer. IEEE Trans. Dielectr. Electr. Insul. 2015, 22, 639-648. [CrossRef]

5. Xu, J.; Howard, M.J.; Mittal, V.; Bates, F.S. Block copolymer micelle toughened isotactic polypropylene. Macromolecules 2017, 50, 6421-6432. [CrossRef]

6. Zhang, Z.-C.; Deng, L.; Lei, J.; Li, Z.-M. Isotactic polypropylene reinforced atactic polypropylene by formation of shish-kebab superstructure. Polymer 2015, 78, 120-133. [CrossRef]

7. Yang, C.; Zhe, X.; Zhang, M.; Wang, M.; Wu, G. Radiation effects on the foaming of atactic polypropylene with supercritical carbon dioxide. Radiat. Phys. Chem. 2017, 131, 35-40. [CrossRef]

8. He, M.; Wang, Q.; Zhao, W.; Zhao, C. A substrate-independent ultrathin hydrogel film as an antifouling and antibacterial layer for a microfiltration membrane anchored via a layer-by-layer thiol-ene click reaction. J. Mater. Chem. B 2018, 6, 3904-3913. [CrossRef] [PubMed]

9. Zhang, C.; Bai, Y.; Cheng, B.; Liu, W. Adhesion properties of atactic polypropylene/acrylate blend copolymer and its adhesion mechanism for untreated polypropylene materials. Int. J. Adhes. Adhes. 2018, 80, 7-15. [CrossRef]

10. Tsou, C.-H.; Yao, W.-H.; Hung, W.-S.; Suen, M.-C.; De Guzman, M.; Chen, J.; Tsou, C.-Y.; Wang, R.Y.; Chen, J.-C.; $\mathrm{Wu}, \mathrm{C}$.-S. Innovative plasma process of grafting methyl diallyl ammonium salt onto polypropylene to impart antibacterial and hydrophilic surface properties. Ind. Eng. Chem. Res. 2018, 57, 2537-2545. [CrossRef]

11. Ščetar, M.; Kurek, M.; Režek Jambrak, A.; Debeaufort, F.; Galić, K. Influence of high power ultrasound on physical-chemical properties of polypropylene films aimed for food packaging: Barrier and contact angle features. Polym. Int. 2017, 66, 1572-1578. [CrossRef]

12. Siracusa, V.; Ingrao, C. Correlation amongst gas barrier behaviour, temperature and thickness in BOPP films for food packaging usage: A lab-scale testing experience. Polym. Test. 2017, 59, 277-289. [CrossRef]

13. Leelaphiwat, P.; Auras, R.A.; Burgess, G.J.; Harte, J.B.; Chonhenchob, V. Preliminary quantification of the permeability, solubility and diffusion coefficients of major aroma compounds present in herbs through various plastic packaging materials. J. Sci. Food Agric. 2018, 98, 1545-1553. [CrossRef] [PubMed]

14. Chen, W.X.; Yu, J.S.; Hu, W.; Chen, G.L. Partial hydrophilic modification of biaxially oriented polypropylene film by an atmospheric pressure plasma jet with the allylamine monomer. Appl. Surf. Sci. 2016, 387, 957-964. [CrossRef]

15. Hu, W.; Bai, Y.; Zhang, C.; Li, N.; Cheng, B. Coating based on the modified chlorinated polypropylene emulsion for promoting printability of biaxially oriented polypropylene film. J. Adhes. Sci. Technol. 2018, 32, 50-67. [CrossRef]

16. Chen, W.X.; Yu, J.S.; Chen, G.L.; Qiu, X.P.; Hu, W.; Bai, H.Y.; Shao, J.Z. Development of a novel protocol for the permanent hydrophilic modification of a BOPP film for high quality printing with water-based ink. RSC Adv. 2015, 5, 87963-87970. [CrossRef]

17. Kalapat, N.; Amornsakchai, T.; Srikhirin, T. Surface modification of biaxially oriented polypropylene (BOPP) film using acrylic acid-corona treatment: Part II. Long term aging surface properties. Surf. Coat. Technol. 2013, 234, 67-75. [CrossRef]

18. Dai, L.; Xu, D. Polyethylene surface enhancement by corona and chemical co-treatment. Tetrahedron Lett. 2019, 60, 1005-1010. [CrossRef] 
19. Kalapat, N.; Amornsakchai, T. Surface modification of biaxially oriented polypropylene (BOPP) film using acrylic acid-corona treatment: Part I. Properties and characterization of treated films. Surf. Coat. Technol. 2012, 207, 594-601. [CrossRef]

20. Rocca-Smith, J.R.; Karbowiak, T.; Marcuzzo, E.; Sensidoni, A.; Piasente, F.; Champion, D.; Heinz, O.; Vitry, P.; Bourillot, E.; Lesniewska, E.; et al. Impact of corona treatment on PLA film properties. Polym. Degrad. Stab. 2016, 132, 109-116. [CrossRef]

21. Popelka, A.; Novák, I.; Al-Maadeed, M.A.S.A.; Ouederni, M.; Krupa, I. Effect of corona treatment on adhesion enhancement of LLDPE. Surf. Coat. Technol. 2018, 335, 118-125. [CrossRef]

22. Sun, C.; Zhang, D.; Wadsworth, L.C. Corona treatment of polyolefin films-A review. Adv. Polym. Technol. 1999, 18, 171-180.

23. Vishnuvarthanan, M.; Rajeswari, N. Effect of mechanical, barrier and adhesion properties on oxygen plasma surface modified PP. Innov. Food Sci. Emerg. Technol. 2015, 30, 119-126. [CrossRef]

24. Mercado-Cabrera, A.; Jaramillo-Sierra, B.; López-Callejas, R.; Valencia-Alvarado, R.; de la Piedad-Beneitez, A.; Peña-Eguiluz, R.; Barocio-Delgado, S.; Muñoz-Castro, A.; Rodríguez-Méndez, B. Surface modification of polypropylene fiber for hydrophilicity enhancement aided by DBD plasma. Prog. Org. Coat. 2013, 76, 1858-1862. [CrossRef]

25. Navaneetha Pandiyaraj, K.; Ram Kumar, M.C.; Arun Kumar, A.; Padmanabhan, P.V.A.; Deshmukh, R.R.; Bah, M.; Ismat Shah, S.; Su, P.-G.; Halleluyah, M.; Halim, A.S. Tailoring the surface properties of polypropylene films through cold atmospheric pressure plasma (CAPP) assisted polymerization and immobilization of biomolecules for enhancement of anti-coagulation activity. Appl. Surf. Sci. 2016, 370, 545-556. [CrossRef]

26. Pandiyaraj, K.N.; Selvarajan, V.; Deshmukh, R.R.; Gao, C. Modification of surface properties of polypropylene (PP) film using DC glow discharge air plasma. Appl. Surf. Sci. 2009, 255, 3965-3971. [CrossRef]

27. Navaneetha Pandiyaraj, K.; Deshmukh, R.R.; Arunkumar, A.; Ramkumar, M.C.; Ruzybayev, I.; Ismat Shah, S.; Su, P.-G.; Periayah, M.H.; Halim, A.S. Evaluation of mechanism of non-thermal plasma effect on the surface of polypropylene films for enhancement of adhesive and hemo compatible properties. Appl. Surf. Sci. 2015, 347, 336-346. [CrossRef]

28. Zhang, D.; Sun, Q.; Wadsworth, L.C. Mechanism of corona treatment on polyolefin films. Polym. Eng. Sci. 1998, 38, 965-970. [CrossRef]

29. Ding, L.; Shao, L.; Bai, Y. Deciphering the mechanism of corona discharge treatment of BOPET film. RSC Adv. 2014, 4, 21782-21787. [CrossRef]

30. Sellin, N.; de Campos, J.S.C. Surface composition analysis of PP films treated by corona discharge. Mater. Res. 2003, 6, 163-166. [CrossRef]

31. Barbaro, G.; Galdi, M.R.; Di Maio, L.; Incarnato, L. Effect of BOPET film surface treatments on adhesion performance of biodegradable coatings for packaging applications. Eur. Polym. J. 2015, 68, 80-89. [CrossRef]

32. Louzi, V.C.; de Campos, J.S.C. Corona treatment applied to synthetic polymeric monofilaments (PP, PET, and PA-6). Surf. Interfaces 2019, 14, 98-107. [CrossRef]

33. O'Hare, L.-A.; Leadley, S.; Parbhoo, B. Surface physicochemistry of corona-discharge-treated polypropylene film. Surf. Interface Anal. 2002, 33, 335-342. [CrossRef]

34. Navaneetha Pandiyaraj, K.; Selvarajan, V.; Deshmukh, R.R.; Gao, C. Adhesive properties of polypropylene (PP) and polyethylene terephthalate (PET) film surfaces treated by DC glow discharge plasma. Vacuum 2008, 83, 332-339. [CrossRef]

35. González, L.T.; Longoria-Rodríguez, F.E.; Sánchez-Domínguez, M.; Leyva-Porras, C.; Acuña-Askar, K.; Kharissov, B.I.; Arizpe-Zapata, A.; Alfaro-Barbosa, J.M. Seasonal variation and chemical composition of particulate matter: A study by XPS, ICP-AES and sequential microanalysis using Raman with SEM/EDS. J. Environ. Sci. 2018, 74, 32-49. [CrossRef]

Publisher's Note: MDPI stays neutral with regard to jurisdictional claims in published maps and institutional affiliations. 